\title{
13 Pathways for inclusive wildfire response and adaptation in northern Saskatchewan
}

\author{
Heidi Walker, Maureen G. Reed, \\ and Amber J. Fletcher
}

\section{Introduction}

Extreme climate-related events are often stimuli for the development of disaster risk reduction and climate change adaptation strategies (IPCC, 2012; Wise et al., 2014). Developing these strategies is complex, involving multiple actors and institutions across scales and jurisdictions that may have differing priorities, objectives and decision-making authorities. While scientific-technical approaches that reduce the proximate causes of risk often dominate these processes, scholars and practitioners are increasingly recognising the need for transformational change to address the structural and systemic causes of risk and vulnerability (Nalau and Handmer, 2015; O'Brien et al., 2015; Pelling et al., 2015; Heikkinen et al., 2018).

Responding to this need, 'adaptation pathways' approaches examine

whether systemic change is needed and the role of incremental adaptation in achieving this; and raising awareness and understanding of the interplay between knowledge, values, power and agency to inform responses to change, particularly in dynamic, complex and contested contexts.

(Wise et al., 2014, p. 327)

Pathways approaches recognise that past responses to hazards shape current and future trajectories. Such responses are also imbued with power relations, which affect who and what is represented in adaptation processes (Fazey et al., 2016), and also how they are represented (Cox et al., 2008). Feminist scholarship on climate change impacts and adaptation, for example, recognises that institutional policies and practices are shaped by power relationships associated with gender, class and race (Kaijser and Kronsell, 2014; Ravera et al., 2016). These relationships enable and constrain the availability of certain adaptation pathways and result in different outcomes and experiences across social groups.

In this chapter, we apply insights from literature on adaptation pathways and feminist literature on climate change to examine how past responses to a major wildfire event in a jurisdictionally complex region of northern Saskatchewan, Canada, inform current and future adaptation processes and trajectories. Drawing

DOI: $10.4324 / 9781003052821-13$ 
from interviews with community residents and government representatives, we examine how emergency and wildfire management institutions facilitated or constrained pathways for adaptation and how these were shaped by dominant knowledges and values. Ultimately, we consider the implications of these predominant pathways for diverse social groups and whether a transformation is required for building inclusive adaptation processes as communities continue to live with fire in the future.

\section{Adaptation pathways and the role of institutions}

Institutions are an important site for understanding how the development of various adaptation pathways are constrained or enabled (Pelling et al., 2015). In this chapter, we define institutions as the "rules of the game" - the rules, norms and practices - that structure political, social and economic life' (Chappell and Waylen, 2013, p. 599). Formal institutions include policies, programmes, regulations and authorities which are influenced by informal institutions such as sociocultural norms, values and knowledge systems (Reed et al., 2014). Institutions for hazard response and adaptation are shaped by historical processes and power relations, resulting in institutional inertia that may constrain policy and practice (Burch et al., 2014; Clarke et al., 2016). Furthermore, it is important to critically examine the informal relations that underpin formal institutional practice in order to recognise whether and what fundamental shifts are needed to achieve desirable futures (O’Brien, 2012).

Gender is an institutionalised system of power that, in turn, shapes other institutions (Chappell and Waylen, 2013). Informal institutions are gendered, and these gendered norms and expectations become embedded within formal institutions for climate change mitigation and adaptation (Ravera et al., 2016). For example, the dominant framing of climate change as a technical, scientific and security problem is underpinned by masculine norms, which has meant that solutions have often been relegated to traditionally male-dominated sectors, such as public safety and infrastructure (Macgregor, 2010). Accordingly, responses and adaptation to climate hazards have centred on strategies to reduce physical exposure and structural damage, which are led by male-dominated professions and activities (e.g., engineered solutions, firefighting) (Enarson, 2016).

Feminist intersectionality theory recognises that gender interacts with other axes of identity and power, such as race, ethnicity and socio-economic status, to influence climate change institutions (Kaijser and Kronsell, 2014). Pease (2016) noted that the masculinised nature of climate change response intersects with Western rationalist and instrumentalist ideologies, resulting in hierarchical, rule-based procedures based on external 'expertise' (e.g., professional firefighting authorities) over local knowledges and priorities (Paveglio et al., 2015). As a consequence, the contributions, values and knowledge of people who fall outside the norms of 'external experts', such as women and Indigenous people, are often excluded.

Gendered and culturally hegemonic wildfire institutions have very real, but often difficult-to-see, influences on adaptation trajectories. For example, Tyler 
and Fairbrother (2013, p. 113) pointed out that wildfire response, policy and practice in Australia are typically 'assumed to have emanated from objective and empirical, if not scientific, bases but this does not take into account the fact that emergency management, bushfire response and fire-fighting, remain overwhelmingly male-dominated areas'. They found that where national policy promoted the household decision between early evacuation and 'stay-and-defend', men were far more likely than women to stay-and-defend-largely due to pressure to conform to dominant masculine norms and expectations. Early evacuation, by contrast, was viewed as a weaker, feminised response. Interestingly, Tyler (2019) observed that despite greater fatality rates among men during past wildfire events in Australia, the 'extremely gendered' nature of wildfire management institutions has meant a continued emphasis on masculinised 'fight' approaches to wildfire preparedness and planning, with less attention on preparedness for early evacuation. The study noted community engagement programmes geared towards empowering women to stay-and-defend. However, such programmes are based on the assumption that women either lack the knowledge of wildfire preparedness or are more amenable than men to behaviour change (Tyler, 2019), highlighting how masculine norms underpin formal institutions, creating an institutional 'stickiness' that reinforces certain development pathways (Mackay et al., 2010). Programmes promoting stay-and-defend presume an ideal solution, which is based on masculine practices. Importantly, such dynamics are context-specific. For example, in countries like Canada where mandatory evacuation is the preferred policy response to major wildfire events, gendered institutional dynamics likely operate in different ways.

The adaptation pathways approach identifies key decisions and interventions over time, along with the informal institutions that underpin these processes, to understand how various adaptation pathways are enabled or constrained (Pelling et al., 2015; Fazey et al., 2016; Heikkinen et al., 2018) ${ }^{1}$ (Table 13.1). Adaptation pathways are analysed by the extent of change including resistance, incremental adjustment, or transformation. Resistance is characterised by 'business-as-usual' approaches to adaptation, often involving additional investment in existing infrastructure, social institutions and/or economic flows. Incremental change refers to marginal shifts in these same areas, which enhances flexibility without causing major systemic disruption. While there is still significant debate in climate change scholarship about what is meant by transformation, it can be broadly characterised as a fundamental change to societal structures and power relations (O'Brien, 2012; Heikkinen et al., 2018). Resistance and incremental adaptation are far more common than transformational strategies that address underlying social causes of vulnerability (Wise et al., 2014; Heikkinen et al., 2018).

Dominant adaptation pathways may be identified through the priorities for addressing risk (as well as the framing of risk), the types of knowledge that are centred, and the extent to which existing power relations are maintained or challenged (Table 13.1). Resistance is characterised by a reliance on existing practices, centralised knowledge and the maintenance of existing power structures. Incremental change focuses on the proximate causes of risk, professional 
Table 13.1 Characteristics of adaptation pathways (based on Nalau and Handmer, 2015; Pelling et al., 2015; Heikkinen et al., 2018)

\begin{tabular}{|c|c|c|c|}
\hline & Resistance & Incremental change & Transformation \\
\hline Description & $\begin{array}{l}\text { Follows existing } \\
\text { development } \\
\text { pathways; enhances } \\
\text { investment } \\
\text { in existing } \\
\text { infrastructure, } \\
\text { social institutions } \\
\text { and/or economic } \\
\text { flows }\end{array}$ & $\begin{array}{l}\text { Marginal shifts to } \\
\text { infrastructure, } \\
\text { social institutions } \\
\text { and/or economic } \\
\text { flows }\end{array}$ & $\begin{array}{l}\text { Fundamental changes } \\
\text { to existing societal } \\
\text { structures }\end{array}$ \\
\hline $\begin{array}{l}\text { Priorities for } \\
\text { addressing } \\
\text { risk }\end{array}$ & $\begin{array}{l}\text { Risk viewed as } \\
\text { routine, relies on } \\
\text { existing methods } \\
\text { and practice; } \\
\text { resources devoted } \\
\text { to maintaining } \\
\text { status quo and } \\
\text { system stability }\end{array}$ & $\begin{array}{l}\text { Risk viewed as } \\
\text { non-routine, } \\
\text { acknowledges need } \\
\text { for improvement } \\
\text { to existing } \\
\text { practice; addresses } \\
\text { proximate causes } \\
\text { of risk and } \\
\text { vulnerability } \\
\text { (e.g. physical } \\
\text { infrastructure) }\end{array}$ & $\begin{array}{l}\text { Risk viewed as complex } \\
\text { and unbounded; } \\
\text { addresses structural } \\
\text { and root causes of risk } \\
\text { and vulnerability (e.g. } \\
\text { power hierarchies, } \\
\text { social and economic } \\
\text { relationships) }\end{array}$ \\
\hline Knowledge & $\begin{array}{l}\text { Conventional; } \\
\text { centralized control } \\
\text { over information }\end{array}$ & $\begin{array}{l}\text { Professional and } \\
\text { specialized } \\
\text { expertise; may } \\
\text { include some } \\
\text { participatory } \\
\text { elements }\end{array}$ & $\begin{array}{l}\text { Trans-disciplinary, } \\
\text { whole-of-society } \\
\text { response; highly } \\
\text { participatory }\end{array}$ \\
\hline Power relations & $\begin{array}{l}\text { Existing structures } \\
\text { maintained }\end{array}$ & $\begin{array}{l}\text { Existing structures } \\
\text { maintained; new } \\
\text { issues may be } \\
\text { introduced }\end{array}$ & $\begin{array}{l}\text { Fundamental changes to } \\
\text { existing structures }\end{array}$ \\
\hline Advantages & $\begin{array}{l}\text { Provides stability and } \\
\text { certainty }\end{array}$ & $\begin{array}{l}\text { Enhances system } \\
\text { diversity and } \\
\text { flexibility and can } \\
\text { incrementally } \\
\text { open new policy } \\
\text { options without } \\
\text { major systemic } \\
\text { disruption }\end{array}$ & $\begin{array}{l}\text { Opens up new policy } \\
\text { options; re-orients } \\
\text { development pathways } \\
\text { towards sustainability } \\
\text { and social justice }\end{array}$ \\
\hline Disadvantages & $\begin{array}{l}\text { Reduces flexibility } \\
\text { over time; adopts } \\
\text { narrow options and } \\
\text { worldviews }\end{array}$ & $\begin{array}{l}\text { Prioritizes functional } \\
\text { persistence; } \\
\text { does not address } \\
\text { underlying } \\
\text { institutions } \\
\text { that contribute } \\
\text { to systemic } \\
\text { vulnerability }\end{array}$ & $\begin{array}{l}\text { May introduce } \\
\text { unexpected outcomes } \\
\text { and instability as } \\
\text { systems reach new } \\
\text { equilibria; requires } \\
\text { constant monitoring, } \\
\text { reflection and renewal }\end{array}$ \\
\hline
\end{tabular}


expertise and maintenance of existing power structures, though it may include some new issues and participatory elements. Transformation is characterised by an emphasis on the root causes of risk and vulnerability, highly participatory approaches and major changes to existing power structures. The priorities for addressing risk, the types of knowledges recognised, and power relations shape, and are shaped by, formal and informal institutions for climate change adaptation. From the transformational perspective, pathways that reinforce existing forms of inequality and marginalisation are increasingly seen as undesirable and an indicator of the need for major structural change (e.g. Tschakert et al., 2013; O'Brien et al., 2015). Therefore, it is necessary to 'shed light on and problematise norms and underlying assumptions that are naturalised and regarded as common sense, but build on and reinforce social categorisations and structures of power, not least through institutional practices' (Kaijser and Kronsell, 2014, p. 428).

\section{5's wildfires in northern Saskatchewan}

In 2015, prolonged dry conditions resulted in a rash of over 700 wildfires across the Canadian province's northern boreal forest region and the largest evacuation the province had ever experienced. The La Ronge region of northern Saskatchewan was one of the areas most impacted by the 2015 fires; it is also a place particularly notable for its jurisdictional complexity. Its population centre is a tri-community that includes a town (La Ronge), northern village (Air Ronge) and First Nation (Lac La Ronge Indian Band [LLRIB]), with a total population of approximately 6,000 . While the three communities within the population centre are politically distinct, they are to some extent socially integrated and share some key services. In addition to its main population in the tri-community, the LLRIB also comprises five smaller satellite communities with a total population of over 3,000.

The community leaders jointly issued a mandatory wildfire evacuation order in early July of 2015, spurring residents to evacuate on their own to stay with family and friends elsewhere or by bus to urban evacuation centres. Four of the five LLRIB satellite communities were also either partially or fully evacuated, as were nearby unincorporated subdivisions and lakeside cabins. Once the evacuation was called, in addition to local governments and organisations, provincial and federal government departments and agencies, the national police service, the Canadian Army, municipal firefighting agencies and non-government organisations (e.g. the Red Cross) became involved with the evacuation and emergency response. Residents spent anywhere between two weeks and one month outside of their community. Ultimately, about 100 cabins were destroyed in surrounding areas, but the tri-community itself experienced no major physical damage and no serious injuries were incurred by either residents or emergency responders.

\section{Method}

Our research was conducted three years after the fires. The lead author lived in the region for 16 months and conducted 44 semi-structured interviews with 
community members and local government representatives who had experienced, or been involved with, the wildfires. The interviewees were identified through established key community contacts, archived media reports and other relevant documents (e.g. local emergency plan). Ten interviews were with key local and provincial government and agency representatives, including from local governments (municipal, village), LLRIB government, local and First Nation agencies (Fire service, Indigenous social service agency) and provincial government agencies (e.g. wildfire management). These actors represent a unique viewpoint, as they were both local residents of the tri-community and key actors in response efforts during or after the wildfire event. Interviews focused on the roles, responsibilities and responses of the representatives' respective organisations during and after the wildfire event. The remaining 34 interviews took place with local residents from the tri-community and surrounding areas and focused on their experiences of the fires. Participants were selected based on stratification by location (jurisdiction of residence at the time of the fires). We also ensured the participation of women, men, Indigenous and non-Indigenous residents. Additional demographic characteristics, such as age, income and length of residency were collected through a participant checklist following each interview. Interviews were transcribed verbatim and coded using a primarily inductive approach aided by NVivo 12 qualitative data analysis software. Direct quotes that illustrate the findings indicate the speakers' gender and community of residence, but names and identifying information have been removed to maintain participants' confidentiality.

\section{Looking to past wildfire responses to learn for future adaptation trajectories}

At the local level, adaptation pathways in the La Ronge area appear to be predominately characterised by resistance and incremental change to infrastructure and institutions. During and after the wildfire event, the emphasis was on the proximate causes of risk and professional and specialised expertise was most heavily relied upon. Though some participatory elements and new issues, such as impacts to the local business community, were evident, existing institutional power relationships have largely remained intact and have resulted in the continued exclusion of certain voices, knowledges and values.

\section{Priorities for addressing risk}

The risk priorities for the La Ronge wildfires were characterised by elements of resistance and incremental change. The emphasis remained on the proximate causes of risk and vulnerability during and after the event, as evidenced by the framing of wildfire as an immediate threat and the prioritisation of physical infrastructure to mitigate future exposure to fire. During the fires, a local Emergency Operations Centre committee was convened, which was comprised of local government leaders and administrators with advising and supporting roles from 
other regional (e.g. the tri-community fire service), provincial (e.g. Wildfire Management, Emergency Management \& Fire Safety, Transportation, Health, Social Services) and federal (e.g. police) jurisdictions. The committee appears to have adopted hierarchical structures and a focus on the immediate physical risks associated with the fires. In the words of one participant who was involved in the emergency operations:

[Emergency Operation Centre meetings] are wonderful things to watch and listen to. People are quickly identified and everybody gives a brief report, but if somebody asks a question and says 'Can you give me help?', 'Okay, you two handle that on a sidebar [conversation] when we are done, but let's get through the common briefing'. So, it is well managed and I didn't feel there were obvious gaps. Now that is in terms of the emergency management.

(male emergency operations representative)

As the participant continued, it became clearer that emergency management in this case was framed primarily as an issue of ensuring the health, safety and welfare of citizens as related to the immediate threat (i.e. the proximate cause of risk) of fire within the community:

There were necessary sidebar conversations about social services support for the evacuees, which was a concern of the Lac La Ronge Indian Band that could and should be addressed in separate conversations. I think the Chief wanted some of that addressed at the big table, but we didn't need to all be there for that.... She has a valid point, but at the briefing I think raise the matter, identify who do I get help from and then afterwards get that help. My approach to it is much more of a command-and-control - we are here to share information and then go do my work.

From this perspective, social services and community supports are considered peripheral to 'big table' conversations.

Since 2015, additional measures have been taken to enhance the preparedness for, and mitigation of, wildfire risk within the tri-community area. When asked about adaptation measures that had occurred in and around their communities, participants most commonly referred to a significant uptick in fuel management projects. Fuel management is a core component of FireSmart, a nation-wide programme aiming to balance the 'natural role [of fire] with the protection of human life, property and economic values' (FireSmart Canada, 2020). It involves the thinning or removal of vegetation to mitigate the severity, intensity and spread rates of fire around communities. Many local residents and government representatives expressed enthusiasm for the additional fuel management projects that had been implemented, which is likely, to some extent, due to its successful application in the nearby unincorporated subdivision of Wadin Bay. Relatively few homes and cabins were lost in that community in 2015, which was largely attributed to the three fuel management 
treatments completed as part of its FireSmart planning efforts in the previous year (Ault et al., 2017).

But the FireSmart program is great and I think it should do more.

(woman, Air Ronge)

they call it FireSmart, you know [LLRIB] actually started cleaning up in the trees a bit between the communities, which I think is good.

(man, LLRIB)

As discussed later in this chapter, however, FireSmart was not uniformly supported by community members, some of whom questioned its effects on the landscape and associated values.

The prioritisation of the proximate causes of risk during the fires appeared to set the stage for the continued emphasis of these issues in the recovery and longer-term adaptation phases following the event, indicating an adaptation pathway characterised by resistance. The risk was narrowly defined through a professional emergency management discourse and subsequent adaptation efforts have been technical in nature. Through a feminist lens, such approaches value masculinised realms of expertise while community concerns are problematically sidelined (Pease, 2016). However, the increasing scale to which these wildfire mitigation initiatives are applied and somewhat expanding opportunities for public participation - as discussed in the following section - suggest elements of incremental change.

\section{Knowledge}

Professional and specialised knowledge was prioritised after the wildfire event, though as time progressed, there were some additional opportunities for public engagement in debriefing and wildfire mitigation efforts. For example, two local public engagement sessions occurred shortly after the event, which provided opportunities for debriefing between local residents and key decision-makers. These sessions focused primarily on the frontline fire operations, economic impacts of the fires and the role of the local business community. The town of La Ronge held the first session, which focused on providing information and answering questions about how fires had been handled within the community. Experts from sectors that played key roles in frontline firefighting efforts were present to provide additional information.

We did a presentation on behalf of [the] mayor and council on what our response was and what we did and why we did certain things. There were also representatives from the fire department, wildfire management, conservation officers, not in an official capacity but there in case there was a question that we needed background information.

(male municipal government representative) 


\section{Walker, Reed, and Fletcher}

The La Ronge and District Chamber of Commerce - an organisation that advocates for businesses in La Ronge, LLRIB, and Air Ronge - provided a second opportunity for resident engagement. The meeting addressed feelings that the local business community had been excluded from decision-making throughout the fire event, as the following resident indicated:

One of my beefs is what I would consider businesses that had a role to play were shut down and kicked out of town. I think that is a huge mistake. I mean the first thing you do in a panic situation is try to surround yourself with people who can contribute and help you out. Kicking out the guy who owns the hardware store and has the parts, the rental store that rents water pumps - kicking those people out of town I would say actually hinders your efforts and doesn't have to.

(male resident, La Ronge)

The meeting provided an opportunity for some community residents - in this case, local business owners - to express their concerns and provide suggestions for enhanced inclusion going forward. To some extent, recognition of these concerns and the need to maintain economic stability throughout a major event gained attention within government agencies.

We have had some in the business community offer their insights.

(male municipal government representative).

One of the things we would like to do is involve our local businesses ... so that they are not handcuffed when an evacuation does happen and they can still make a bit of a profit or keep their doors open when they come back to the community after the evacuation.

(male provincial government representative).

As mentioned in the previous section, when the immediate urgency of the event faded and the communities began a return to normal life, action for local wildfire preparedness and adaptation predominately involved fuel treatment activities within the tri-community region. Two local municipal leaders pointed out that relatively little action had occurred across local jurisdictions since 2015, indicating that the region primarily relied on the knowledge and expertise of the provincial wildfire management agency for wildfire planning and development of adaptation strategies.

I don't think we've sat down with the three communities and said this is what we're going to do next time this happens. So, I think that definitely needs to be done.

(male municipal government representative)

The main concern is that we are going to wait too long. It is kind of going to be like the Shakespearean tragedy where we are going to be sitting there 
and we are going to be thinking about what we should do rather than actually taking some action items seriously and by the time the next fire rolls through, we don't have a solid plan. So that is definitely the number one concern that I have.

(male municipal government representative)

The strong existing institutional arrangements for FireSmart practice have enabled some opportunities for community participation. The FireSmart Communities Program, for instance, supports local residents in the development of a local FireSmart Board, a community protection plan and community FireSmart events (FireSmart Canada, 2020). Before the 2015 fires, the resort subdivision of Wadin Bay was the only community in the La Ronge region to hold FireSmart Community Recognition status. Spurred by the success of the programme in Wadin Bay, two other unincorporated subdivisions in the La Ronge region have also joined the FireSmart Communities Program since 2015, providing some opportunity for local participation in wildfire preparedness.

\section{Power relations}

While some participatory elements were evident, existing power dynamics were more or less maintained, resulting in the exclusion of some social groups, experiences and values during and after the event. Differentiated experiences at the intersection of location, culture and gender were apparent, as participants reported prioritisation of central communities over satellites, marginalisation of Indigenous and local knowledge and values and failure to acknowledge women's contributions.

During the fires, LLRIB was not only concerned about its main population centre within the tri-community, but also the four of its five outlying satellite communities that were partially or fully evacuated. Historical inequalities associated with colonisation in Canada have resulted in significant economic discrepancies between Euro-Canadian and Indigenous populations, especially those living on reserves (Wilson and McDonald, 2010), which meant that compared to La Ronge and Air Ronge, LLRIB played a larger role in organising transportation to evacuation centres and ensuring the welfare of its residents throughout the wildfire event. Frustration with the lack of attention to wellbeing - for example, 'where 3,000 people went and whether 3,000 people were okay and whether this mom who was nine months pregnant was sleeping on the floor' (female LLRIB government representative) - at local emergency operations committee meetings was clear. This participant elaborated to say:

The focus very much became La Ronge. We [LLRIB staff] were having a meeting in the morning with regards to our outlying communities, then we would go to [La Ronge] council chambers and have a meeting there with regards to an update on the tri-community, and then we would go to [the evacuation registration hub] and continue to do registrations and coordination and 
answer calls. Then there would be another meeting at about 6:00 pm with regards to what was happening with the outlying communities. So it got to be a lot of meetings, but what happened was that [La Ronge and Air Ronge] couldn't have cared less about what was happening in Grandmother's Bay, Hall Lake, or Stanley Mission - they just wanted to talk about what was happening in the tri-community. That is all that mattered to them. ... It was very interesting to see our tri-community really separate and have different opinions on what was important and what wasn't important.

The dominant approach to wildfire management may, therefore, have prioritised the immediate threat of fire in the areas surrounding the main population centres, rather than the secondary impacts residents experienced after evacuation, which may have been particularly pronounced for many LLRIB residents from the satellite communities who relied on evacuation by bus and accommodation at large urban evacuation centres. While the prioritisation of response to the proximate causes of risk was successful insofar as no serious physical injuries were sustained, such models may deny local agency, knowledge and culturally relevant mechanisms for dealing with risk (Scharbach and Waldram, 2016). These models may also lead to the exclusion of certain communities - in this case, smaller Indigenous communities located further away from centres of decision-making.

The public engagement sessions after the event, to some extent, opened up new policy directions (e.g. consideration of impacts to the business community). However, the retrospective discussions about how the fires were handled within the community again revealed an institutional inertia that emphasised response to the immediate risk of fire and centring of the male-dominated sectors who responded to this risk (e.g. municipal and wildland firefighting agencies). Contributions such as cooking, cleaning, delivering meals, caring roles, rebuilding social fabric and responding to mental and emotional health impacts were most often performed by women, but often less recognised than the maledominated sectors' 'frontline' responses. For some women, these contributions also occurred at the intersection of gendered roles and Cree cultural norms, such as for the following woman who volunteered at the LLRIB evacuation hub to provide meals for residents and emergency workers:

[helping in this way] is something I feel is a cultural thing. That would be something my grandmother would do - at her cabin and you would see a boat coming, [she would] turn the coffee on and get cookies out ... Anybody that came over had to have coffee or food and for our family that is such a big thing, so to me it was just absolutely normal - when you go anywhere and see somebody helping you, you do what can what you can to give back to them.

(woman, LLRIB member)

As she continued, her frustration at the lack of acknowledgement such contributions received was clear: 'not once were [LLRIB and the volunteers] recognised in the media or recognised anywhere'. Likewise, two women who were interviewed together 
had engaged in caring work during the fires and noted the lack of attention that their contributions received in formal engagement and decision-making processes.

Participant 1: I mean in all fairness, for sure protecting the property and people is number one, but we just wanted them to be inclusive of everything. (woman, La Ronge)

Participant 2: but as far as afterwards, the leadership - they all had their own experience with the wildfire situation too. For sure it was stressful for everybody and they had lots on their plates, but if you have a group of people that have stepped up you would think there would be some acknowledgement of that and just learning from the experience because it hadn't been done before. (woman, La Ronge)

As an alternative to the more top-down engagement sessions, some community members expressed a desire to see more collaborative engagement inclusive of the diverse experiences and contributions of community residents.

I don't feel we are going to be any better prepared for the next time because they are not asking the right questions to the right people ... I would have liked to see a public consultation from the groups that were here. What worked for you? What didn't work for you? Like a think tank or brainstorming session ... rather being from a finger-pointing point of view, more of a constructive look at it, but there hasn't been anything like that.

(woman, LLRIB member)

We need to identify both strengths during the last event and build on them and areas to improve in the future. We need to include dialogue with trappers and traditional people.

$$
\text { (man, La Ronge) }
$$

Longer-term adaptation initiatives fell within FireSmart's mandate to protect life, property and economic values, indicating a continued emphasis on the proximate causes of risk and pathways characterised by resistance and incremental change. Many of the fuel management projects completed in and around the tri-community have not fallen under the FireSmart Communities Program, which means that project development and completion were led by the provincial wildfire management agency with input and approval by community leadership. Shortly after a fuel treatment was implemented near her neighbourhood, one resident shared the grief she felt through the loss of place where she frequently went to collect medicinal plants, lead land-based education programmes for children and spend time with family and friends. She especially lamented the lack of engagement with local residents prior to completion of the fuel management project.

We have these spaces within our community that are like stepping off grid and into an untouched piece of paradise. I spend much of my time exploring 
these places and sharing this love of the boreal with my family and with families in my community. The threat of forest fires has always been a part of my life here in La Ronge and four years ago the threat caused us to evacuate our home and leave most of what we had behind. The important things were with me though, the irreplaceable family members. Since the fires, I have seen our tree population around town dwindle as we become a 'fire smart' community. This has involved the thinning of trees in places that surround residential areas and will supposedly slow the spread of fire as it will have less fuel. This past winter, an area by my house that I frequent daily fell victim to this practice. ... The heart-breaking part about it is that there was no consultation or warning before the trees were taken. The land was stripped of diversity, left defenceless against the winds, and all in the name of saving 'things'.

(woman, Air Ronge)

Another resident expressed concern that a singular reliance on fuel treatments has eclipsed other approaches for building adaptive capacity, such as proactive emergency preparedness and planning.

I am worried about people taking fire protection to the extreme now. I think we need an emergency plan and an emergency response and an understanding that this is climate change and this is what we have to come to face, but not to battle it [by] clear cutting the whole area.

(woman, unincorporated subdivision).

These concerns challenge an underlying assumption that the protection of physical structures and economic assets are the principal - or only - values residents wish to maintain. It also indicates that the prioritisation of these issues may exclude the diverse social groups and the non-material values they hold for areas immediately adjacent to their communities. One participant explicitly cited the need to bridge diverse knowledges and experiences as wildfire preparedness and adaptation progresses:

It is not to go back 50 years to live like we did, but there are things that were done for a reason and that wisdom I think can be brought, but we have sort of let too much of that go. ... computers and hard evidence-based scientific knowledge are not everything. It is wonderful - I am not saying that we shouldn't have those kinds of statistics and that kind of work, we need that also - but we need more common sense and what worked in the past and let's carry that forward.

(woman, unincorporated subdivision)

This sentiment, along with other noted examples, indicates that there is an apparent appetite for more transformative change to include a broader range of voices and issues. 


\section{Discussion}

That adaptation pathways were characterised by resistance and incremental change is not overly surprising, as major wildfires are commonly framed as technical problems and approached with technical solutions and sectoral expertise (Bosomworth, 2015; Nalau and Handmer, 2015). A feminist institutional lens indicates that this framing itself is gendered and, although historically male-dominated sectors may have formal rules that include diverse groups, masculinised norms can shape the development of institutions and sectors to the disadvantage of women and other non-conforming groups (Kronsell, 2016). The resulting norms, then, give rise to institutional inertia that is 'reinforced over time and often come to be deeply embedded in organisations and dominant modes of political action and understanding' (Pierson, 2004, p. 11).

The emphasis on the proximate causes of risk proved highly effective for preventing fatalities during the 2015 fire season, but institutional inertia resulted in a continued singular emphasis on proximate risks over the longer term. Although some opportunities for public participation emerged, focus remained 'on creating solutions within domains dominated by men' (Cox et al., 2008, p. 477). In this case, these solutions arose from and supported wildfire management agencies and local business. This also meant that the active contributions made by groups outside of 'frontline' work, such as caring roles often performed by women due to gendered expectations and socialisation, were largely excluded from public discussion and debriefing following the fires.

Our data also revealed the intersectional nature of power embedded within institutional practice for wildfire response and adaptation. The primary emphasis on reducing physical harm through the rapid removal of residents from their communities was reminiscent of Scharbach and Waldram's (2016, p. 66) observation that wildfire risk and response in Saskatchewan is based on a Western model of risk, 'conceptualised synchronically in response to acute challenges (i.e., an impending, immediate threat); once out of harm's way, risk is no longer the operative factor for dealing with evacuees'. How histories of colonisation contributed to different responsibilities across local jurisdictions, and how impacts and losses were experienced in diverse ways by women, men, youth and Elders after removal from their communities, were either absent or considered peripheral to local emergency management discussions. Women's contributions to wildfire response often went unrecognised while longer-term adaptations have neglected broader systems of meaning and knowledge associated with the landscape. Intersectionality, therefore, shaped not only the material impacts of the wildfire, but also the dominant discourse shaping wildfire response and adaptation (Moosa and Tuana, 2014).

Many of the impacts and losses experienced due to environmental change and hazard events are nonmaterial and nonquantifiable, such as those to mental and emotional health, self-determination and influence and sense of place (Turner et al., 2008; Tschakert et al., 2019). In a previous analysis, we found that these nonmaterial impacts and losses in La Ronge were experienced differently across 
intersections of location, gender, ethnicity, age, and access to financial resources and influenced by broader structures such as gendered norms and expectations and histories of colonisation (Walker et al., 2020). However, diverse experiences remained largely invisible in formal debriefing and decision-making processes, such as in the public engagement sessions following the fires.

Power dynamics have consequences for which and whose experiences, knowledges and values were included or excluded as communities prepare for fire in the future. Longer-term adaptation efforts (e.g., FireSmart) integrate some level of community participation. Globally, such programmes have played a role in enhancing fire preparedness and, in some circumstances, have also contributed to social cohesion, self-efficacy and resilience (Haynes et al., 2020). However, fire management is conceptualised by this programme primarily through a physical-infrastructural lens, which may not necessarily account for local ecological knowledge and values attached to the natural environment (Bosomworth, 2018). Fuel management projects are located in close proximity to La Ronge tri-community neighbourhoods - often the most accessible natural spaces for residents, which may be used and valued in diverse ways by different social groups within the community. Reliance on FireSmart as the sole means of engagement limits the kinds of considerations that are accounted for in future planning for wildfires or long-term adaptation measures that communities might adopt. If adaptation initiatives only respond to risks to physical and economic assets and are implemented primarily by external agencies, the nonmaterial values that diverse social groups hold for the natural areas immediately adjacent to their communities, which contribute to individual and community health, wellbeing, and resilience, may also continue to be impacted. Where local knowledges and values are not recognised, mistrust toward external agencies may also impede future response efforts (Paveglio et al., 2015).

While no evidence of transformative change was evident in the La Ronge study, residents' cited need for more inclusive planning, including the bridging of local, traditional and external knowledge indicated a desire for transformation. Findings that demonstrated the exclusion of certain values and experiences also indicate a need for transformation - 'fundamental shifts in power and representation of interests and values' (Pelling, 2011, p. 84). Implementing both incremental and transformative forms of adaption is one way forward, though attention is needed to how these may constrain one another (Wise et al., 2014; Hadarits et al., 2017). It may also be necessary to examine equity in power relations by 'questioning and challenging fixed beliefs, values, stereotypes, identities and assumptions especially about who is able to participate in adaptation planning, whose knowledge counts and who suffers the consequences of specific choices' (Ajibade and Adams, 2019, p. 856). As described in the results, this includes explicit attention to how informal institutions, including gendered and western norms and power relations, intersect to shape institutional policy and practice for emergency and wildlife management (Waylen, 2014).

Transformation requires more than just greater participation in existing institutions (Haynes, Bird and Whittaker, 2020). Rather, it necessitates changes to 
participation itself, including highly participatory visioning and decision-making that a) centres local knowledges, values and experiences, especially those that exist at the intersections of multiple forms of oppression, and b) takes a learning-oriented approach. First, centring local knowledges and experiences can make institutionalised forms of inequality visible, and can even transform them (Jacobs, 2019). Historically marginalised groups, such as Indigenous women, are also actively responding to the effects of climate change and hazards in their communities, as was evident in the La Ronge study. Prioritising these forms of leadership in environmental decision-making can also help to rebalance power relations that are steeped in the legacies of colonisation (Whyte, 2014; Dhillon, 2020).

Second, chasms may exist between the 'expert' knowledge of disaster risk reduction and the local knowledge and embodied experiences of altered local spaces, raising the need for strategies that foster learning and knowledge co-production (Tschakert et al., 2016). Both individual and social learning are necessary for effective adaptation processes and can be facilitated through collaborative planning that fosters multi-directional knowledge transfer, critical reflection and collective dialogue (Armitage et al., 2011; Tschakert et al., 2013). Even highly participatory processes, however, do not necessarily result in transformative outcomes as they are not immune to intra- and inter-group power dynamics or the tendency to focus on technical/infrastructural solutions, which may reproduce existing forms of inequality and vulnerability (Godfrey-Wood and Naess, 2016; Tschakert et al., 2016). Explicitly integrating consideration of structural inequalities into dialogue and reflection processes and employing methodological innovations that draw on embodied and affective experiences may help address these challenges (Tschakert et al., 2016).

\section{Conclusion}

Past responses to wildfire in the La Ronge region have focused on the proximate causes of risk and the actors and specialised knowledges that respond to those risks. Some limited opportunities for public engagement expanded the range of issues considered (e.g. to include economic impacts on the local business community). However, the authoritative emphasis on proximate causes of risk, physical and economic impacts and professional knowledge indicated that adaptation trajectories continue to be characterised by resistance and incremental change. While highly effective for basic harm reduction, this emphasis has constrained transformation during recovery and longer-term planning, thus missing opportunities to address root causes of risk and vulnerability. The pathways characterised by resistance and incremental change have been constructed with Western and masculine norms, resulting in the exclusion of certain voices, knowledge and experiences. These include the contributions of women - especially Indigenous women - to the emergency response efforts and the nonmaterial impacts of wildfire and evacuation that are experienced in diverse ways across intersections of gender, ethnicity, socio-economic class and age. 


\section{Walker, Reed, and Fletcher}

Lack of transformation at the local level to date does not necessarily mean that it is not occurring at other societal scales or over longer time periods (Heikkinen et al., 2018). Indeed, a short-term study undertaken three years after an event may be insufficient to track transformative change. However, current approaches that continue to exclude certain voices, knowledges, and experiences, and which reinforce existing forms of inequality, indicate the need for more immediate transformative approaches to inform inclusive adaptation processes at the local scale. Such approaches include the development of highly participatory decisionmaking processes that are learning-oriented and centre local knowledges, values and experiences. The establishment of participatory processes in the quiescent times between major events can both contribute to more inclusive and transformative adaptation and inform improved immediate response to future wildfire events.

\section{Acknowledgement}

This chapter draws on research supported by the Social Sciences and Humanities Research Council of Canada.

\section{Note}

1 Heikkinen et al (2018) delineate categories of incremental, reformistic and transformative change, which are comparable to Pelling et al's (2015) categorisations of resistance, incremental change and transformation, respectively.

\section{References}

Ajibade, I., and Adams, E.A. (2019) 'Planning principles and assessment of transformational adaptation: Towards a refined ethical approach', Climate and Development, 11(10), pp. 850-862.

Armitage, D., Berkes, F., Dale, A., Kocho-Schellenberg, A. and Patton, E. (2011) 'Co-management and the co-production of knowledge: Learning to adapt in Canada's Arctic', Global Environmental Change, 21, pp. 995-1004.

Ault, R., Baxter, G. and Hsieh, R. (2017) Wildfire Tested Fuel Treatments 2015: Weyakwin and Wadin Bay, Saskatchewan. Point-Claire, Canada: FP Innovations.

Bosomworth, K. (2018) 'A discursive-institutional perspective on transformative governance: A case from a fire management policy sector', Environmental Policy and Governance, 28, pp. 415-425.

Bosomworth, K. (2015) 'Climate change adaptation in public policy: Frames, fire management, and frame reflection', Environment and Planning. part C, 33, pp. 1450-1466.

Burch, S., Shaw, A., Daleb, A. and Robinson, J. (2014) 'Triggering transformative change: A development path approach to climate change response in communities', Climate Policy, 14(4), pp. 467-487.

Chappell, L. and Waylen, G. (2013) 'Gender and the hidden life of institutions', Public Administration, 91(3), pp. 599-615. 
Clarke, D., Murphy, C. and Lorenzoni, I. (2016) 'Barriers to transformative adaptation: Responses to flood risk in Ireland', Journal of Extreme Events, 3(2), pp. 1650010.

Cox, R.S., Long, B.C., Jones, M.I. and Handler, R.J. (2008) 'Sequestering of suffering: Critical discourse analysis of natural disaster media coverage', Journal of Health Psychology, 13, pp. 469-480.

Dhillon, C.M. (2020) 'Indigenous feminisms: Disturbing colonialism in environmental science partnerships', Sociology of Race and Ethnicity, 6(4), pp. 483-500.

Enarson, E. (2016) 'Men, masculinities, and disaster: An action research agenda', in Enarson, E. and Pease, B. (eds.) Men, Masculinities, and Disaster, pp. 219-233. Abingdon, Oxon and New York, NY: Routledge.

Fazey, I.R.A., Wise, R.M, Lyon, C., Campeanu, C., Moug, P. and Davies, T.E. (2016) 'Past and future adaptation pathways', Climate and Development, 8(1), pp. 26-44.

FireSmart Canada. (2020) What is FireSmart? [online]. Available at: https://firesmartcan ada.ca/what-is-firesmart/ (Accessed: 29 October 2020).

Godfrey-Wood, R. and Naess, L.O. (2016) 'Adapting to climate change: Transforming development?', IDS Bulletin, 47(2), pp. 49-62.

Hadarits, M., Pittman, J., Corkal, D., Hill, H., Bruce, K. and Howard, A. (2017) 'The interplay between incremental, transitional, and transformational adaptation: A case study of Canadian agriculture', Regional Environmental Change, 17, pp. 1515-1525.

Haynes, K., Bird, D.K. and Whittaker, J. (2020) 'Working outside 'the rules': Opportunities and challenges of community participation in risk reduction', International Journal of Disaster Risk Reduction, 44, p. 101396.

Heikkinen, M., Ylä-Anttila, T. and Juhola, S. (2018) 'Incremental, reformistic or transformational: What kind of change do $\mathrm{C} 40$ cities advocate to deal with climate change?', Journal of Environmental Policy Eु Planning, 21(1), pp. 90-103.

IPCC. (2012) Managing the Risks of Extreme Events and Disasters to Advance Climate Change Adaptation. Cambridge and New York: Cambridge University Press.

Jacobs, F. (2019) 'Black feminism and radical planning: New directions for disaster planning research', Planning Theory, 18(1), pp. 24-39.

Kaijser, A. and Kronsell, A. (2014) 'Climate change through the lens of intersectionality', Environmental Politics, 23(3), pp. 417-433.

Kronsell, A. (2016) 'Sexed bodies and military masculinities: Gender path dependence in EU's common security and defense policy', Men and Masculinities, 19(3), pp. 311-336.

Macgregor, S. (2010) 'A stranger silence still: The need for feminist social research on climate change', Sociological Review, 57, pp. 124-140.

Mackay, F., Kenny, M. and Chappell, L. (2010) 'New institutionalism through a gender lens. Towards a feminist institutionalism?', International Political Science Review, 31(5), pp. 573-588.

Moosa, C.S. and Tuana, N. (2014) 'Mapping a research agenda concerning gender and climate change: A review of the literature', Hypatia, 29(3), pp. 677-694.

Nalau, J. and Handmer, J. (2015) 'When is transformation a viable policy alternative?', Environmental Science E Policy, 54, pp. 349-356.

O'Brien, K. (2012) 'Global environmental change II: From adaptation to deliberate transformation', Progress in Human Geography, 36(5), pp. 667-676.

O'Brien, K., Eriksen, S., Inderberg, T.H. and Sygna, L. (2015) 'Climate change and development: Adaptation through transformation', in Climate Change Adaptation and Development: Transforming Policies and Practices. pp. 273-289. Abingdon, Oxon and New York, NY: Routledge. 


\section{Walker, Reed, and Fletcher}

Paveglio, T.B., Carroll, M.S., Hall, T.E. and Brenkert-Smith, H. (2015) 'Put the wet stuff on the hot stuff: The legacy and drivers of conflict surrounding wildfire suppression', Journal of Rural Studies, 41, pp. 72-81.

Pease, B. (2016) 'Masculinism, climate change and 'man-made' disasters', in Enarson, E. and Pease, B. (eds.) Men, Masculinities, and Disaster. Abingdon and New York: Routledge, pp. 21-33.

Pelling, M. (2011) Adaptation to Climate Change: From Resilience to Transformation. New York: Routledge.

Pelling, M., O’Brien, K. and Matyas, D. (2015) 'Adaptation and transformation', Climatic Change, 133(1), pp. 113-127.

Pierson, P. (2004) Politics in Time. History, Institutions and Social Analysis. Princeton: Princeton University Press.

Ravera, F., Iniesta-Arandia, I., Martín-López, B., Pascual, U. and Bose, P. (2016) 'Gender perspectives in resilience, vulnerability and adaptation to global environmental change', Ambio, 45(S3), pp. 235-247.

Reed, M.G., Scott, A., Natcher, D. and Johnston, M. (2014) 'Linking gender, climate change, adaptive capacity, and forest-based communities in Canada', Canadian Journal of Forest Research, 44(9), pp. 995-1004.

Scharbach, J. and Waldram, J.B. (2016) 'Asking for a disaster: Being 'at risk' in the emergency evacuation of a Northern Canadian Aboriginal Community', Human Organization, 75(1), pp. 59-70.

Tschakert, P., Ellis, N.R., Anderson, C., Kelly, A. and Obeng, J. (2019) 'One thousand ways to experience loss: A systematic analysis of climate-related intangible harm from around the world', Global Environmental Change, 55, pp. 58-72.

Tschakert, P., Das, P.J., Shrestha Pradhan, N., Machado, M., Lamadrid, A., Buragohain, M. and Hazarika, M.A. (2016) 'Micropolitics in collective learning spaces for adaptive decision making', Global Environmental Change, 40, pp. 182-194.

Tschakert, P., van Oort, B., St. Clair, A.L. and LaMadrid, A. (2013) 'Inequality and transformation analyses: A complementary lens for addressing vulnerability to climate change', Climate and Development, 5(4), pp. 340-350.

Turner, N.J., Gregory, R., Brooks, C., Failing, L. and Satterfield, T. (2008) 'From invisibility to transparency: Identifying the implications', Ecology and Society, 13(2), p. 7.

Tyler, M. and Fairbrother, P. (2013) 'Bushfires are 'men's business': The importance of gender and rural hegemonic masculinity', Journal of Rural Studies, 30, pp. 110-119.

Tyler, M., Carson, L. and Reynolds, B. (2019) 'Are fire services 'extremely gendered' organizations? Examining the Country Fire Authority (CFA) in Australia', Gender, Work EB Organization, 26, pp. 1304-1323.

Walker, H.M., Reed M.G., and Fletcher, A.J. (2020) 'Applying intersectionality to climate hazards: A theoretically informed study of wildfire in northern Saskatchewan', Climate Policy,21(2), 171-185. .

Waylen, G. (2014) 'Informal institutions, institutional change, and gender equality', Political Research Quarterly, 67(1), pp. 212-223.

Whyte, K.P. (2014) 'Indigenous women, climate change impacts, and collective action', Hypatia, 29(3), pp. 599-616.

Wilson, D. and MacDonald, D. (2010) The Income Gap Between Aboriginal Peoples and the Rest of Canada. Ottawa: Canadian Centre for Policy Alternatives.

Wise, R.M., Fazey I., Stafford Smith, M., Park, S.E., Eakin, H.C., Archer Van Garderen, E.R.M., Campbell, B. (2014) 'Reconceptualising adaptation to climate change as part of pathways of change and response', Global Environmental Change, 28, pp. 325-336. 